\title{
The Role of Narratives in Collaborative Innovation - Transitions towards Relational Forms of Dementia Care
}

\author{
Maria Taivalsaari Røhnebæk \\ maria.rohnebak@inn.no | Inland Norway University of Applied Sciences, Postboks 400, 2418 Elverum, \\ Norway
}

\begin{abstract}
This article advances the relevance of a narrative approach in studies of collaborative innovation. The narrative approach outlined is based in translation theory, developed within science and technology studies (STS) and organizational studies. The research is based in a case study of an innovation initiative in municipal elderly care in Norway. The case study follows the implementation processes of the initiative in three elderly care institutions. Various forms of resistance were encountered in the implementation process, and the analysis shows how narrative strategies worked as brokering mechanisms in negotiations of this resistance. The article explores how a collaborative innovation process evolves through interplays between strategic narratives and counter narratives and contributes by demonstrating how narratives may work as important brokering mechanisms in collaborative innovation processes. The article discusses finally how and why narrative approaches may contribute to research on collaborative innovation, and it outlines managerial implications.
\end{abstract}

Keywords. Collaborative innovation; Translation; Narratives; Narrators; Relational care.

Cite paper as: Røhnebæk, M. T., (2020). The Role of Narratives in Collaborative Innovation - Transitions towards Relational Forms of Dementia Care, Journal of Innovation Management, www.openjim.org, 8(3), 28-47. 


\section{Introduction}

This article explores how narratives can play a crucial role in collaborative innovation in the public sector. Collaborative innovation is an undeveloped but emerging field of research, which intersects with a broader paradigmatic shift towards networks, collaborative governance, coproduction and co-creation in the public sector research discourse (Hartley et al., 2013; Osborne, 2006; Torfing et al., 2016; Torfing and Triantafillou, 2013; Voorberg et al. 2015). This shift tends to be presented as a response to the deficits of the New Public Management (NPM) paradigm, which has dominated the development of public services in western countries since the eighties. NPM's focus on performance management, internal control and competitiveness has allegedly led to fragmentation and disintegration, which makes the public service systems unsuited for meeting complex societal problems and the actual needs of citizens and users.

Several scholars suggest that remedies to these deficiencies can be found in the joined forces of various actors within and beyond public sector organizations. Collaboration across organizational boundaries and sectors has become central, and co-creation has become a key term used to highlight the potential of bringing in resources among users, citizens, civil society and public and private actors (Chen et al., 2019; Crosby et al., 2017; Torfing et al., 2016).This is expected to enhance capacity and effectiveness of public services, to spur creativity and innovation and strengthen value creation (Ansell and Gash, 2008; Bommert, 2010; Hartley et al., 2013; Sørensen and Torfing, 2011; Torfing, 2016; 2019).

The concept 'collaborative innovation' draws on theories on 'democratizing innovation' (Von Hippel, 2005) and 'open innovation' (Chesbrough, 2003) developed in the private sector innovation literature. Baldwin and Von Hippel (2011) discuss 'open collaborative innovation' as an alternative to a 'producer's innovation model', which implies that innovations are largely developed by producers and supplied to consumers in the marked. Conversely, 'open collaborative innovation' implies that stakeholders such as users (individuals or firms) are invited to take part in innovation through shared work processes, and the outputs as well as insights on the processes should be publicly accessible.

Similarly, 'collaborative innovation' in the public sector is based on the idea that multi-actor collaboration is key to develop innovative solutions that can tackle various societal challenges and especially 'wicked' problems and cross-cutting policy issues (Crosby et al., 2017; Hartley, et al., 2013; Torfing, 2016; 2019). The literature advances collaborative innovation as preferable to market competition and closed, bureaucratic processes because it mobilizes a broader range of innovation assets such as knowledge, imagination, creativity, courage, resources and transformative capacities (Bommert, 2010; Torfing, 2016; 2019). Thus, 'collaborative innovation' can be broadly defined as innovation enabled through multi-actor collaboration (Torfing, 2019), in which innovation is understood as changes that break with established practices and mind-sets of an organization or organizational field (Hartley et al., 2013).

However, when adopted and developed in the public sector innovation discourse, the term 'collaborative innovation' has become ambiguous as it is outlined as a theoretical approach in studies of public sector innovation, and advanced as a reform strategy for practitioners at the same time (Torfing, 2016; Wegrich, 2018). Moreover, the literature has a clear bias in the sense that 
the dominant focus has been on outlining the advantages of this innovation model rather than empirically examining how it may work in practice (Wegrich, 2018). Hence, the literature is largely conceptual and agenda setting, while there is a lack of empirical research that investigates the nitty-gritty of the practical process involved. Hence, there is need for empirical research of the practices of collaborative innovation, and there is need for development of theoretical perspectives and concepts suitable for studying and analysing collaborative innovation.

This article contributes in this regard by presenting findings from an empirical study set in elderly care, where efforts were made to engage citizens and other stakeholders in innovation and transformations of the elderly care services, within dementia care in particular. The aim of the study was to gain insights on the challenges involved in implementing new practices at the micro level, and to explore suitable ways to conceptualize and theorize the processes that can have more general relevance for understandings of collaborative innovation. The role of narratives was found to be central in the local processes studied, and this was singled out as the main theoretical focus of the study.

The aim of the article is thus twofold: to introduce and discuss the relevance of a narrative approach to collaborative innovation, and to illustrate the relevance of this approach in the analysis of an empirical case of set in municipal elderly care.

To continue, the research context of the study is first presented, followed by an outline of theoretical background and proposed theoretical framework. Next, the data material and methodologies are accounted for, and the empirical findings presented. Implications of the study for collaborative innovation in the public sector are finally discussed.

\section{Research context}

Demographic changes with aging populations create increasing pressure on public health care in western countries, and the growing number of people suffering from dementia cause particularly complex challenges that calls for a range of innovative measures (WHO, 2017). Among others, the prevalence of dementia calls for innovative solutions with regards to awareness of new forms of therapy and caring practices. These solutions include a variety of non-drug therapies and milieu treatment, such as recreational activities, movement, relaxation, arts and music (Gräsel et al., 2003; Kolanowski et al., 2010). Music therapy has gained interest, encouraged by the fact that music is found to work as a substitution for verbal language, and as means for meaningful stimulation (Myskja, 2008; Opie et al., 1999). The emergence and experimentation with new forms of therapy and caring practices, is part of broader transitions towards more 'relational' forms of care as a vital complement to the somatic and medicalized care which dominates the professionalized health care system (Moser, 2010; 2011). Advancing relational care, involves increased focus on the value of socializing, recreation and participation in meaningful activities among dementia patients. This requires mobilization of resources and stakeholders outside the public health care institutions such as volunteers, family carers and other stakeholders in collaborative innovation. This article focuses on one such case of collaborative innovation which involve efforts to implement various forms of milieu treatment in municipal elderly care in Norway. Central to these initiatives was the implementation of Generation Song, a program wherein a group of children 
from local nurseries visited nearby elderly care centres and engaged with the elderly through a regular program consisting of traditional songs with accompanying movements. Moreover, employees were supposed to integrate Generation Song and other music measures also in their daily work without direct support from the nurseries. The music project and implementation of Generation Song was a first step in broader collaborative innovation processes that aimed to engage citizens and stakeholders in development and renewal of the elderly care services.

\section{Theoretical Framework}

\subsection{Collaborative innovation in the public sector}

Collaborative innovation links to the broader field of public sector innovation, which can be understood as the implementation of a product, process, practice, technology, or service that is new to the adopting organization (Osborne and Brown, 2013). Reviews of the literature on public sector innovation, reveals that research literature in this field has been dominated by conceptual publications that seek to grasp the meaning of the concept of innvoation in a public sector context, and to provide overviews and typologies of different forms of innovation (Chen et al., 2019; De Vries et al., 2016). Empirical research on public sector innovation has been scarcer and suffering from too inadequate theoretical anchoring (De Vries et al. 2016). The lack of theoretical anchoring in empirical research implies inadequacies when it comes to establish research dialogues across empirical studies. Still, several empirical studies have aimed to contribute with knowledge on the antecedents of public sector innovation, i.e. seeking to understand the factors that may impede as well as stimulate innovation. This is often captured as identification of drivers and barriers of innovation in the public sector (De Vries et al. 2016).

In the literature on public sector innovation, barriers and drivers are explored from different vantage points. First, some scholars focus on barriers and drivers as related to the specific character of the public sector compared to the private sector (e.g. Halvorsen, et al, 2005; Hartley, 2005). Second, different kinds of governance and public administration paradigms are seen to entail different types of drivers and barriers to innovation (Hartley, 2005; Hartley et al., 2013). Third, empirical studies reveal organizational and sector-specific institutional barriers and drivers, in which different governance and management paradigms typically co-exist and overlap (e.g. Aagaard, 2012).

The research literature on collaborative innovation, as a subset of public sector innovation, prolongs the tendencies to focus on drivers and barriers. Moreover, the collaborative innovation literature has also been largely conceptual and 'agenda setting', advancing collaborative innovation as an advantageous model for innovation (Bommert, 2010; Hartly et al., 2013 Torfing, 2016; 2019). This bias, which assumes positive relations between collaboration, innovation and subsequently improvement (Osborn \& Brown, 2011), has created certain blinds spots in the debates and research on collaborative innovation (Wegrich, 2019). These blind entail risks of failure to see how collaboration may not only be beneficial but also conflicted and problematic. This paves the wave for research examining the details of situated innovation practices, examining how actors encounter and tackle barriers to innovation in practice. Hence, studying the nitty gritty 
involved in the realization and implementation of collaborative innovation constitute a valuable contribution to the research field. I outline next how this can be realized through studies of translations and narratives.

\subsection{Translations and Narratives in Innovation Studies}

Adoption, implementation and spread of innovations, is often linked to concept of diffusion (Rogers (2003 [1962]). However, the term diffusion originates from the natural sciences, where it refers to how particles move from a concentrated area to a less concentrated area by its own force. Translation has been introduced as an alternative and more suitable metaphor for understanding the implementation and spread of innovations (Callon, 1986; Latour 1984, 1991) especially in organizational contexts (Czarniawska and Sevón, 1996; Hepsø, 2007; Røvik, 2007, 2016). The translation metaphor brings attention to the ways in which innovations spread through the active work of translators rather than by their own force, and it emphasizes how innovations are edited and transformed as they spread.

Translation perspectives are embedded in these basic premises, but translation theory has otherwise taken diverse directions in different disciplines (Wæraas \& Nielsen, 2016). The perspective was first developed within science and technology studies (STS) (Callon, 1986; Latour, 1984, 1991, 2005) and later introduced to organizational studies (Czarniawska and Sevón, 1996). Organizational studies based in translation theory focus mainly on the translation processes involved in the transfer of ideas, knowledge and organizational models between organizations and different context, which entail an emphasis on translations as editing, transformations and context sensitivity (Czarniawska and Sevón, 1996; Røvik, 2016; Wæraas and Nielsen, 2016). However, the translation perspective that was originally developed within STS uses the notion of translation to highlight the power struggles, negotiations and persuasions involved in innovation processes. Innovation is seen to rely on the ability to create alliances and mobilize support from various actors, and translation is understood as the alignment of diverse, often contradictory interests (Callon, 1986; Latour, 1986). 'The art of interessement' becomes, in this way, central to translation (Akrich et al., 2002a; Callon, 1986).

The translation perspective, especially in the STS-versions, constitute a foundation and give direction to the narrative approach to be outlined in this article. A narrative approach does not contain one stable set of premises; narrative theory can be used to inform various forms of research, and a narrative approach may refer to a range of research strategies (Boje, 2001; Czarniawska, 1998, 2004; Gabriel 2000). Thus, specifications and clarifications of the narrative approach to be introduced here are needed. Drawing on the insights from research based in translation approaches to innovation, I focus on a narrative approach where narratives, and narrative skills and strategies, constitute a central element in the process of engaging various actors to support the development and implementation of innovations. If translation is seen as processes of bringing together actors through negotiations and persuasions, narration and narratives become the more specified means through which such processes takes place. Focusing on narration and the role of narratives in innovation, thus allow us to zoom in on specific and crucial aspects of barriers or impediments in innovation processes and grasp more precisely how new ideas are translated into innovations. 
Furthermore, in order to focus on narratives, we first need to clarify how the term narrative can be understood. Narratives are essentially the same as stories, and the terms are often used interchangeably. Even so, scholars tend to distinguish between the two. In this article, stories are seen as a subset of narratives (Feldman et al., 2004; Boje, 2001). However, I acknowledge that different kinds of narratives exist, some that are more structured, coherent and plotted than others (Czarniawska, 2004). A plotted story is a story that contains a structure that gives a sense of direction and purpose to events (Czarniawska, 2004). This differentiation between narratives as more or less structured and plotted is central for the approach to be outlined in this article.

Limited scholarly work explores the linkages between public sector innovation and narratives explicitly, but there is some relevant work to draw on. Borins (2009) argues for a narratological approach to public management innovation, and outlines and illustrates one such approach based in key concepts drawn from narratology. He highlights among others the 'narrative polyphony' of innovation processes - different voices may tell stories of the same events in different ways. Moreover, in line with the narrative approach of this article, he points to the potential of focusing on the ways in which practitioners may use narratives to "engage, inspire, persuade or "spin"" (Borins, 2009, p.185).

The latter is also in focus in a study of narratives in public sector innovation carried out by Pedersen and Johansen (2012). They conducted an ethnographic study that focuses on the implementation of a clinical priority system in a hospital emergency ward. In the analysis of the implementation process, they found that the narrative capacities of the initiator were central for the progress of the project. In his role as a spokesperson he managed to develop and disseminate a strategic, plotted and structured narrative that captured and persuaded listeners within and across departments. The dissemination of the strategic narrative was vital for reaching decisions to implement the new model. In the actual implementation process, the strategic narrative was revised and contested through different antenarratives among employees. Antenarratives are described as fragmented stories that are not necessarily structured by a plot, and which can be ambivalent, conflicted and often expressing 'personal polyphony' (Boje, 2008). According to Pedersen \& Johansen (2012) employees involved in innovation process interpret and make sense of change trough such antenarratives. Drawing on among others Weick (1995), they show how fragmented antenarratives can be equally important to the structured and plotted narratives of appointed spokespersons because they are part of the sense-making processes through which employees translate new ideas into change in everyday practices. Moreover, they suggest that antenarratives can take form as counter narratives, that is narratives that contradict and challenge the broader strategic narrative of the innovation process. Counter narratives can be seen as expressions of resistance towards proposed changes.

The differentiation between structured, strategic narratives and everyday antenarratives is drawn from similar distinctions made by Bartel and Garud (2009) who highlight the different roles of structured and provisional narratives in sustaining organizational innovations. They see structured innovation narratives as depictions of past and future innovations conveyed through a clear plot, while provisional innovation narratives are more fragmented depictions of innovation efforts in the making. Furthermore, they suggest that innovation narratives may form 'boundary objects' (Star, 2010) as they may bring together different actors and provide a sense of coherence 
and shared meanings through an underlying plot, while allowing for flexibility and individual interpretations at the same time. Bartel and Garud (2009) argue that the balance between coherence and flexibility takes place through dynamic interactions between structured innovation narratives and dispersed, provisional narratives. In sum they suggest that innovation narratives are vital 'brokering mechanisms' in innovation processes. Focusing on narratives as 'brokers' enable researchers to follow how agency in innovation processes will shift among different people: 'The role of broker is transitory and does not remain located within a specific individual' (Bartel and Garud, 2009, p.115). Following narratives as brokers thus enable researchers to pay attention to the dynamic interactions between individual agency and collective mobilization of resources in innovation.

\subsection{Analytical Lens}

I follow the outlined narrative approach to innovation as suggested by Pedersen and Johansen (2012) and Bartel and Garud (2009), which base their approaches in translation theory and interpretive organizational research. By combining insights from these related approaches, I suggest a specific analytical lens which consist of the following elements: First, I suggest that innovation processes consist of translations that involve 'the art of interessement', (Akrich, 2002b; Callon, 1986). I focus on how the art of interessement is linked to the narrative capacity of dedicated spokespersons and the development of strategic innovation narratives (Akrich et al. 2002b; Pedersen and Johansen, 2012). Second, I follow up on Pedersen and Johansen's (2012) focus on conflicting narratives and explore how innovation processes may progress through an interplay between strategic narratives and counter narratives. Finally, in line with Bartel and Garud (2009), I focus on narratives as 'brokering mechanisms'; understood as negotiation and mediation of conflicting forces, and as means for translating and aligning diverse interests. More specifically, brokering is in this context understood as the intermediation invovled in transforming new ideas to fit new environments (Hargadon and Sutton, 1997).

\section{Methods}

\subsection{Research design and description of the case}

The study was designed as an explorative embedded, single case study, with four embedded units of analysis (Yin, 2009). Case studies are suitable as methodological approach for studies that seek to understand phenomena holistically, within real-life contexts, and from the perspectives of those involved (Stake, 1995; Yin, 2009). Moreover, Eisenhardt (1998) argues that single cases are useful especially in new research contexts or when existing theory seems inadequate. This fits with the knowledge needs identified in the field of collaborative innovation in the public sector, which is still a novel field of research.

Case studies are commonly criticized for being idiosyncratic, and for providing weak foundations for generalizations. However, case studies are aimed at analytical generalization, rather than statistical generalization (Yin, 2009), which implies that the analysis of specific empirical findings 
should connect to broader theoretical constructs by building new theory or by modifying or adding to existing theories. Guided by this reasoning, the single case study was carried out in embedded subunits, which included one project team and three elderly care institutions with three groups of collaborating nurseries (ten nurseries altogether). The case study was conducted when the project had been running for approximately two years.

\subsection{Data collection and data material}

The case study is comprised of observation and qualitative interviews conducted during a period of one year, from June 2014 to June 2015. Semi-structured interviews were carried out with employees in all three units of analysis: 1) the project team, 2) employees in the elderly care institutions and 3) employees and groups of children in the nurseries. The data material consists of 27 interviews, in total. 11 employees in three different elderly care institutions were interviewed, and 9 employees in 9 collaborating nurseries. These interviews lasted from half an hour to two hours, and they were recorded and transcribed. Three group interviews with children from three different nurseries were also conducted. One of these was recorded, and the other two were documented through notes taken during the interview.

The researcher took part in an ongoing dialogue with the project team throughout the year of data collection. This included informal discussions, and meetings on the progress of the project. Four formal semi-structured interviews were also carried out with the project team. The interviews addressed experiences, challenges and perspectives on the process, with regards to the music project and the new collaborative arrangement.

The study also included observations. The researcher participated in Generation Song in all three nursing homes. In one of the nursing homes, observation was conducted three times (on three different occasions). Observation also involved spending time with employees and patients before and after the sessions, which provided valuable insights into the preparations and dynamics at the ward prior to and after the visits from the nurseries. Furthermore, the researcher followed the project team when they spent time at one of the closed wards with the most demanding patient groups. The field observations were documented through detailed field notes. Internal documents such as plans, routines, internal evaluations and funding applications are also part of the data material, as well as readings of policy documents. Thus, the study is based on a triangulation of data that contributes to a holistic understanding of the processes studied (Yin, 2009).

\subsection{Data Analysis}

The data collection process and the analytical process intersect and intertwine in interpretive, explorative research (Alvesson and Skjöldberg, 1994). Thus, the central insights presented in this article emerged gradually during the research process. Still, a more demarcated phase of data analysis took place after the data collection process was completed. The analysis loosely followed principles from grounded theory (Strauss \& Corbin, 1990), which include three types of coding: open coding, axial coding and selective coding. During analysis, elements of the 
data which directly or indirectly concerned drivers (what mobilized and energized the innovation process) and barriers (what hindered or impeded the process) first identified and preliminarily labelled, resembling an open coding process. This resulted in a list of 18 issues related to drivers (energizing factors), and 16 issues related to barriers (hindrances/impediments). Following the principle elements of axial coding, the relations between these issues were further examined, and were then grouped into broader and more analytical categories that were found to encapsulate related issues in the preliminary detailed list. These categories were reduced to four conceptual categories concerning drivers and barriers. Finally, drawing on the principles of 'selective coding' (Corbin \& Strauss, 1990), narratives were identified as a 'core category' and as the central phenomenon of the study. Literature on narratives in organizational theory and innovation studies was further used to guide the analysis (E.g. Bartel and Garud, 2009 Boje, 2001; 2008; Czarniawska, 1998; Czarniawska-Joerges, 2004; Feldman et al., 2004; Pedersen and Johansen, 2012).

Key informants were invited to comment on interpretations and analysis of the data, based on a preliminary data report. They found the interpretations to be accurate and valid, which contributes to strengthen the overall validity and credibility of the analysis (Yin, 2011). Moreover, the iterative analytical process was done in close dialogue with a broader team of researchers involved in similar case studies of collaborative innovation. The analysis resonated with dynamics in comparable cases, which strengthen the external validity, i.e. it indicates that the analysis has relevance beyond the immediate case study (Yin, 2009). Still, despite these measures for ensuring validity, it is certain that other theories would also be relevant for analyzing this case, and the perspective taken affect which aspects of the case that are highlighted. Thus, it should be stressed that the story of this case could look different through another theoretical lens.

\section{The Case}

\subsection{Background}

The objective of Generation Song was to establish a set arrangement in which a group of children from local nurseries visited nearby elderly care centres and engaged with the elderly through a regular program consisting of traditional songs with accompanying movements. Moreover, the employees at the elderly care centres were to perform the same program twice a day at fixed hours, even when the nurseries were not visiting.

In addition, the Generation Song initiative involved, more broadly, efforts to create awareness of the various ways in which music could be used in therapeutic measures in daily care for the elderly. This involved individual programs in which the patients' preferences of and reactions to various forms of music were documented, and individual CDs were created for use in the patients' rooms. Moreover, singing and music was to be explored as means for easing various daily care situations. The project aimed to systematize the use of music in care and treatment, which also involved pressure to visualize and document such measures as an active part of the treatment process. Thus, the objective was to reduce the random and individual-dependent way of using music in care that characterized practices of the past. 
Generation Song was developed and introduced as a pilot program - a first step among several initiatives aimed at promoting milieu treatment as a central part of elderly care in the municipality. This was to be enabled through interactions between the public services, volunteers in the local community and civil society. The nurse who initially introduced these ideas was eventually granted a project leader position. She led and coordinated the project(s) with a project team consisting of two co-workers: one preschool professional and one nurse. The music project was based on the research, perspectives and teaching of Audun Myskja (2008; 2011), a medical doctor with a PhD in integrated music in nursing homes. Myskja was enrolled as a mentor and supervisor of the project and arranged training for the health care employees.

\subsection{Generation Song in a Narrative Perspective}

\section{The spokesperson}

Generation Song originated from a nurse who worked in one of the elderly care institutions. She returned to her position as a nurse after working several years for a non-profit organization. The nurse's entrepreneurial behaviour was a central driving force in the inception of the idea for Generation Song and for the development of the project. This seemed especially linked to her strong narrative capacities, which enabled her to inspire and engage people to believe in the new idea. For instance, the way in which the project was presented at the outset by the project manager was stated by the nurseries as the main reason for why they wanted to join in on Generation Song. The staff at one of the nurseries explained:

They came here and talked about it and explained, and we were all in tears because of the way she presented it. She stressed how important this is, and then we were like; 'but of course we want to join in on this!'

In addition to convincing the employees and the children at the nurseries to join in on Generation Song, the project leader also had to convince the employees in the elderly care institutions to integrate the model in their daily work. Thus, the project leader had to mobilize support from various actors. Her ability to do so seemed linked to her narrative capacities, but more specifically to the ability to construct a storyline about Generation Song and to translate this story into different versions depending on the audience. I refer to this as emplotments.

\section{Emplotment and interessement}

A plotted story is a story that contains a structure that gives a sense of direction and purpose to events (Czarniawska, 2004). Thus, the plotted story of Generation Song is a story that articulates why Generation Song is worth spending resources on seen from various standpoints. To create interest for Generation Song, the spokesperson (project leader) drew together various plotlines. Emphasising on different plotlines meant that the presentation of Generation Song was adjusted to the audiences. A central plotline introduced Generation Song as valuable because it worked 'just like medicine'. This plotline was particularly effective when convincing the nurseries to join in, as explained by one nursery employee:

She was very good at explaining to the kids that they were doing a job. She explained that 
the singing was like medicine for the elderly and that it meant a lot to them throughout the day that they had been visiting.

This description of the children's involvement as a 'job' and the singing as 'medicine for the elderly' appeared repeatedly in the data material - in interviews with the health workers and, in particular, among the children and employees at the nurseries. A child at one of the nurseries explained the reasons for taking part in Generation Song as follows:

Because we want the old people to be happy, and because it's like medicine. The songs are like medicine (...) It's an important job so we just sing!

These phrases originated from the project leader and the project team. The ways in which the terms were repeatedly paraphrased among the involved participants indicate that the initiators had managed to frame the project in a manner that captured the listeners. The simplicity of the 'singing is like medicine' plotline may be one reason to why it was effective in creating interest and engagement among children and employees in the nurseries. But the story of Generation Song also consisted of other more advanced plotlines. Introducing Generation Song was legitimized with reference to neuroscience research, which has documented positive effects of the use of music on brains with cognitive impairments caused by dementia (Gräsel et al., 2003).

Moreover, analysis of internal project documents and applications for external funding revealed that the initiative was framed in the current public policy discourse through explicit anchoring in calls for action formulated in the Official Norwegian Report 'Innovation in Care' (NOU 2011:11) and the related white paper 'Future Care' (Meld. St. 29 (2012-2013), 2013). The document studies of the case show that these green and white papers emphasize the innovation potential in municipal elderly care and find among others that mobilization of resources in civil society offers promising solutions for dealing with the increased pressure on public care services. Generation Song and related initiative in the municipality was presented as concrete responses to call for innovation action at the policy level. These more advanced plotlines, based in findings from clinical research and the policy discourse was important for creating interest and support among health care mangers at different levels, and consequently for ensuring financing and necessary structures for the realization of Generation Song.

\section{Resistance and 'counter narratives'}

While the plotting of Generation Song was successful in creating interest among key actors, the plotted narrative was also met with resistance to the proposed changes among participants, especially frontline employees. This resistance can be captured as 'counter narratives', and the central counter narratives to the Generation Song was articulated among the health care employees. A central counter narrative was related to timing and time pressure.

Time pressure related to the total workload throughout the working day, and the degree of flexibility available for prioritizing what to do and when to do it. To make external collaboration work, fixed schedules were necessary, since the involved parties had to be synched. This required a rigidity that some found too demanding. This was partly due to the heavy workloads and time pressures throughout the day. As one of the employees explained:

I felt that the fixed timing was hard, the fact that we have to do it within this set time limit, when you know that you have a thousand things to do. And it takes time to manage it, 
to get everyone gathered in a way, and then there are lots of things happening at the same time, which also needs to be taken care of. Then I felt stressed at times.

Adhering to a fixed schedule also felt demanding because the workload varied from day to day depending on the health status of the patients:

It varies significantly among the patients, how demanding they are - it may vary from day to day how much time we have to spend with each of them.

On the other hand, without a fixed timing for Generation Song, it seemed all-too-easy for the arrangement to fade away. One of the centres did not manage to sustain Generation Song within the ward as a regular activity without the nurseries. One employee saw this as partly regretful:

We could do this group singing and stuff-we do have time for that, given that we don't have to follow fixed timings and a very detailed routine that has to be followed. So we should actually do that. We should sit down, when say we have like five minutes, and then we should actually just do it.

This statement indicates that time was perhaps not actually a decisive impediment to why the Generation Song initiative was met with some resistance. Given room for a certain flexibility, employees could have done it, as explained by the employee above. This was further confirmed in an interview with one of her colleagues:

It [Generation Song] has somewhat stopped due to the current heavy workloads, which create a different time pressure. It does not necessarily take too much time to do these things, but the focus is elsewhere - the focus is on nursing (...) so it has basically not been prioritized. However, there are some of us who are conscious about using songs, and about using what we have learned. But I see that there are lots of others who don't.

Even though timing and time pressure were repeatedly mentioned as impeding factors, another central counter narrative was related the different personalities and attitudes among the employees, and their professional boundaries. Lack of commitment was found to be rooted in emotional distress related to the fact that many employees found singing scary and embarrassing. One employee elaborated on this in the following manner:

They say that they don't have time for it, but I think it is rather about anxiety -there is something about not being good enough. When we sing, we make a fool of ourselves - we are on thin ice. It is so much easier to just walk around and hand out medication. I get the feeling that when we sing, we are stepping out of the comfort zone.

The above quote indicates that the initiative, in some ways, challenged established professional roles and boundaries, and this was used as a way of explaining resistance among some employees. As one nurse points out:

Some think this is just ridiculous. They think it takes up too much time, they don't feel like it, and they think some of us are just over the top. We go into this with different personalities, and some are very enthusiastic, and you're not supposed to be too excited around here. So that has been a problem.

Hence, while the most clearly expressed counter narratives was related to timing and time pres- 
sure, the subtler and underlying counter narratives were related to professional boundaries and anxiety and unease with taking on a new role and 'embarrassing' tasks.

\section{Narratives as 'brokering'}

Generation Song was met with resistance and counter narratives mainly among health care employees. As indicated above, this can be linked to the fact that the project challenged conventional professional norms, by which some employees felt uncomfortable with taking on tasks beyond their regular designated role. Within the elderly care institution, the use of music and movements was easily accepted and valued as entertainment and recreation among the health care employees. However, integrating music treatment in daily care practices, and as part of the procedural work routines at the wards, proved challenging. When one of the project team members attempted to deal with the lack of documentation of music measures at one of the wards, the manager and employees explained that they had not implemented any such measures, so there was nothing to document. The project team member explained:

I thought this sounded strange, so I asked them, 'Well tell me about your experiences then. Do you have any good examples of experiences with music?' And then all these things came up. For instance, there is this man with motoric and movement disabilities, which makes it difficult for him to walk. Then they found that if they sing 'Napoleon and his army' [a traditional children's song] and use the clear beat and rhythm of the song, then he can follow the beat and he is able to start walking. So, each time they use this song, they see that it has improved his movement abilities. He is even able to walk alone without a walker or support from a nurse. Well then this is a measure I tell them!

Eliciting and circulating such stories, which portrayed visible effects and results in daily care situations, turned out to be crucial for mobilizing internal support for the innovation project. The same examples were elaborately referred to in different interviews and came to work as internal 'evidence' that the music project was desirable and effective. The following quote from one of the health care employees is illustrative:

I am going to tell you a story, which you might have heard already. We had two patients who were extremely difficult. One of them was so angry with me that I thought he would hit me. I even think he did. Then I started singing 'Row, row, row your boat...' and then a colleague came on the other side and joined in. We continued with other songs as well, and suddenly he stood up and said: 'I am sorry that I was angry with you'. Something just happened when we sat there singing - he realized that he had been angry with me and he apologized (...) So this works - there is no doubt about it.

She continued to describe various examples from daily care situations, and highlighted how such stories were picked up and used by the project team:

The project leader often tells this story about how we were sitting there on each side of the bed, because this happened - so that's that.

Capturing and distributing daily care narratives that demonstrated the direct effects and practical implications of the music project, worked in this way as brokering mechanisms (Bartel and Garud, 2009) that contributed negotiate and align the different perceptions among various actors. This brokering took place through informal communication among the employees, but 
was also used by the project leader in more formal presentations of the project both within the health care department of the municipality and externally.

\section{Closing Discussion}

The case study illustrates how a dedicated spokesperson with strong narrative capacities can be crucial for moving a collaborative innovation initiative forward. Furthermore, the case provides insights to how the construction of a strategic innovation narrative involves various forms of plotting, which gives purpose and meaning to the initiative. By drawing together various plots, the project team constructed a strategic narrative that could be adjusted to different audiences. Thus, the strategic narrative had the capacity to mobilize support from very different actors. Even so, the strategic narrative was met with a certain resistance among health care workers, and this resistance was negotiated through the means of daily care narratives which 'proved' the effectiveness of using music in dementia care.

The daily care narratives served in this way an important 'brokering mechanisms' which contributed to sustaining the Generation Song initiative. Bartel and Garud (2009) has pointed out how perceptions of narratives as brokers, as opposed to individuals as brokers, enable us to see how agency shifts across different people as innovation processes unfold. The narratives that were effective as brokering mechanism circulated among people involved in the project and were picked up and used by the project leader and official spokesperson and integrated with the strategic narrative. This highlights how a focus on narratives can be effective for capturing the mechanisms that bring actors together in innovation processes, which includes the role of individuals but moves beyond the mere performances of individuals.

Pedersen and Johansen (2012) see narratives that contradict, challenge and run counter to strategic narratives as important for innovation processes because it creates room for reflection and sense making. While strategic innovation narratives create order, counter narratives are important because they leave room for disorder. While these insights are valuable, it needs to be acknowledged that resistance and counter narratives may also create barriers that undermine innovation processes. Exploring how narratives can work as brokers between strategic narratives and counter narratives, can give insights to subtle forms of resistance which is not necessarily clearly articulated in counter narratives. In this case the subtler but central resistance were linked to conventional professional boundaries and identities.

As pointed out, and illustrated, barriers or hindrances to implementation of Generation Song seemed linked to the higher status of medicalized and somatic care as opposed to the relational care practices that can be associated with milieu treatment initiatives such as Generation Song. Considering this, it is interesting to see how the coining of the phrase 'singing is just like medicine' also played a part in the brokering of resistance. The strength of this catchphrase was visible in the way it repeatedly appeared in conversations, interviews and presentations. The phrase can be seen as 'winning through' due to its simplicity, but it is also worth noticing that the innovation was framed and conceptualized in relation to the dominant care paradigm that favours somatic and medicalized care. The music project was not presented in contrast to the prevailing paradigm, the initiators of the innovation project enabled the new idea to move forward by 
rhetorically aligning the new practices with the prevailing norms and structures. This clearly illustrates how narratives may serve as brokering, i.e. as intermediation which contributes to transform new ideas to fit new environments (Bartel and Garud, 2009; Hargadon and Sutton, 1997).

\subsection{Research implications}

The study and analysis have various implication for innovation research and research on collaborative innovation in particular. First, focusing on narratives is a way of bringing forward the polyphony of voices in innovation processes, i.e. the myriad of perceptions among different actors, which require contextual interpretations. Exploring this polyphony enables researchers to pay attention to the different perceptions and aspects of innovations, which may downplay the tendency of positive normativity underlying the public sector innovation literature in general and the collaborative innovation literature in particular. Next, using narratives as entrance to explore mechanisms that hinder as well as mobilize innovation may enable researchers to capture drivers and barriers at micro levels as well as structural levels, as insights on constraining and enabling structures can be found in the interpretations of narratives among actors at the micro level. Moreover, a focus on the role of narratives in innovation processes enables researchers to capture drivers and barriers as dynamic relations between individual agency and collective mobilization.

Regarding collaborative innovation, understanding the role of narration and narratives seems particularly fruitful since such initiatives depend on the ability to mobilize support from various actors often set in radically different institutional contexts. This can involve studies of how central narratives can work as boundary objects which draw people together while allowing for dissonance and diverse interpretations of change processes at the same time (Bartel \& Garud, 2009; Star, 2010). Understanding how narrative capacities and the ability to construct strategic narratives affect collaborative innovation can thus be crucial for understanding the initiation, implementation and sustainability of such initiatives. Hence, the kind of narrative approach to innovation introduced and explored in this article deserves further research attention as it gives as access to study the varied and unpredictable trajectories of collaborative innovation.

\subsection{Managerial implications}

Finally, there are some key practical and managerial implications to be drawn from this study and analysis. First, paying attention to narratives as suggested here, allow managers and participants in innovation processes to understand underlying tensions, resistance and conflicts that may emerge as innovation processes unfolds. Efforts to change existing practices and systems in organizational contexts are likely to involve conflicts and resistance. Such conflicts and resistance can be productive and contribute to shape and move innovations forward, but it may also impede the implementation, scaling and spread of innovations. Narratives may work as brokering mechanisms in this respect, as narratives provide means for translating stated and formal strategies of innovations into adapted versions that align with the organizational context. This highlight 
also the importance of involving skilled narrators in innovation management, that can communicate and create shared understandings of innovation processes. Moreover, in collaborative and open forms of innovation, the role of narrators and narratives seems to be of particular importance as such processes often brings together diverse organizational and individual actors with varied backgrounds. Bringing such actors together towards common and shared goals require translations and alignments through the means of narratives and convincing narrators.

\section{References}

Aagaard, P. (2012) Drivers and barriers of public innovation in crime prevention. The Innovation Journal: The Public Sector Innovation Journal, 17(1), article 6.

Agger, A., \& Lund, D. H. (2017). Collaborative Innovation in the Public Sector-new perspectives on the role of citizens? Scandinavian Journal of Public Administration, 21(3), 17-38.

Akrich, M., Callon, M., \& Latour, B. (2002a). The Key To Success In Innovation Part I: The Art Of Interessement. International Journal of Innovation Management, 6(02), 187-206.

Akrich, M., Callon, M., \& Latour, B. (2002b). The Key To Success In Innovation Part II: The Art Of Choosing Good Spokespersons. International Journal of Innovation Management, 6(2), 207-225.

Alvesson, M., \& Sköldberg, K. (1994). Tolkning och reflektion: Vetenskapsfilosofi och kvalitativ metod. Lund: Studentlitteratur.

Ansell, C., and Gash, A. (2008) "Collaborative Governance in Theory and Practice." Journal of Public Administration Research and Theory 18 (4): 543-571.

Ansell, C., \& Torfing, J. (2014) Public Innovation through Collaboration and Design. New York, NY: Routledge.

Baldwin, C., \& Von Hippel, E. (2011). Modeling a paradigm shift: From producer innovation to user and open collaborative innovation. Organization science, 22(6), 1399-1417.

Bartel, C. A., \& Garud, R. (2009). The role of narratives in sustaining organizational innovation. Organization Science, 20(1): 107-17.

Boje, D. M. (2001). Narrative methods for organizational and communication research. London: Sage.

Boje, D. M. (2008) (Ed.). Storytelling and the future of organizations: An antenarrative handbook. New York: Routledge.

Borins, S. (2011). Making narrative count: A narratological approach to public management innovation. Journal of Public Administration Research and Theory, 22(1): 165-189.

Bommert, B. (2010). Collaborative innovation in the public sector. International Public

Management Review, 11(1): 15-33.

Callon, M. (1986). Some elements of a sociology of translation: Domestication of the scallops 
and the fishermen of St Brieuc Bay. In J. Law (Ed.), Power, action and belief: a new sociology of knowledge? (pp. 296-223). London: Routledge \& Kegan Paul.

Chen, J., Walker, R. M., \& Sawhney, M. (2019). Public service innovation: a typology. Public Management Review, 1-22.

Chesbrough, H. (2003) Open Innovation: The New Imperative for Creating and Profiting from Technology. Cambridge, MA: Harvard Business School Press.

Crosby, B.C., Hart, P. \& Torfing, J. (2017) Public value creation through collaborative innovation, Public Management Review, 19 (5), 655-669.

Czarniawska-Joerges, B. (2004). Narratives in social science research. London: Sage.

Czarniawska, B. (1998). A narrative approach in organization studies. Thousand Oaks, CA: SAGE.

Czarniawska, B., \& Joerges, B. (1996). Travels of ideas. In B. Czarniawska-Joerges \& G. Sevón (Eds.), Translating Organizational Change. New York: Walter de Gruyter.

De Vries, H., Bekkers, V., \& Tummers, L. (2016). Innovation in the public sector: A systematic review and future research agenda. Public administration, 94(1), 146-166.

Eisenhardt, K. M. (1989). Building theories from case study research. Academy of management review, $14(4), 532-550$.

Evald, M. R., Nissen, H. A., Clarke, A. H., \& Munksgaard, K. B. (2014). Reviewing cross-field public private innovation literature: Current research themes and future research themes yet to be explored. International Public Management Review, 15(2), 32-57.

Feldman, M. S., Sköldberg, K., Brown, R. N., \& Horner, D. (2004). Making sense of stories: A rhetorical approach to narrative analysis. Journal of Public Administration Research and Theory, 14(2): $147-70$.

Gabriel, Y. (2000). Storytelling in organizations: Facts, fictions and fantasies. Oxford: Oxford University Press.

Gräsel, E., Wllfang J., \& Kornhuber J. (2003). Non-drug therapies for dementia: An overview of the current situation with regard to proof of effectiveness. Dementia and Geriatric Cognitive Disorders, 15(3), 115-25.

Halvorsen, T., Hauknes, J., Miles, I., \& Røste, R. 2005. On the differences between public and private sector innovation. Publin Report, D9.

Hargadon, A. \& Sutton, R.I. (1997) Technology Brokering and Innovation in a Product Development Firm. Administrative Science Quarterly 42(4), 716-749

Hartley, J. (2005). Innovation in governance and public services: Past and present. Public Money and Management, 25(1): 27-34.

Hartley, J., Sørensen, E., \& Torfing, J. (2013). Collaborative innovation: A viable alternative to market competition and organizational entrepreneurship. Public Administration Review, 73(6), $821-830$. 
Kolanowski, A., Fick, D., Frazer C., Penrod, J. (2010). It's about time: Use of nonpharmacological interventions in the nursing home. Journal of Nursing Scholarship, 42(2), 214-222.

Latour, B. (1984). The powers of association. In J. Law (Ed.), Power, action and belief: A new sociology of knowledge? (pp. 264-280). London: Routledge \& Kegan Paul.

Latour, B. (1991). Technology is society made durable In J. Law (Ed.), A Sociology of monsters: essays on power, technology and domination (pp. 273). London: Routledge.

Meijer, A. (2014). From hero-innovators to distributed heroism: An in-depth analysis of the role of individuals in public sector innovation. Public Management Review, 16 (2), 199-216.

Meld. St. 29 (2012-2013). (2013). Morgendagens omsorg. Oslo: Helse og omsorgsdepartementet.

Moser, I. (2010). Perhaps tears should not be counted but wiped away: On quality and improvement in dementia care. In A. Mol, I. Moser \& J. Pols (Eds.), Care in practice: On tinkering in clinics, homes and farms (pp. 7-24). Bielefeld Transcript Verlag.

Moser, I. (2011). Dementia and the limits to life: Anthropological sensibilities, STS interferences, and possibilities in care. Science, Technology 83 Human Values, 35 (5), 704-722.

Myskja, A. (2008): The day the music died. Nordic Journal of Music Therapy, 17(1), 30-40.

Myskja, A. (2011). Integrated music in nursing homes - an approach to dementia care (Doctoral dissertation). Bergen: University of Bergen.

NOU 2011:11. (2011). Innovasjon $i$ omsorg. Oslo: Statens forvaltningstjeneste. Informasjonsforvaltning.

Opie, J., Rosewarne, R., O'Connor, D.W. (1999). The efficacy of psychosocial approaches to behaviour disorders in dementia: A systematic literature review. The Australian and New Zealand Journal of Psychiatry, 33, 789-799.

Osborne, S. P. (2006). The new public governance? Public Management Review, 8(3), 377387.

Osborne, S., \& Brown, L. (2013) Introduction in S. Osborne \& L. Brown (Eds.) The Handbook of innovation in public services. (pp. 1-9). Cheltenham: Edward Elgar.

Pedersen, A.F., \& Johansen, M.B. (2012). Strategic and everyday innovative narratives: Translating ideas into everyday life in organizations. The Innovation Journal: The Public Sector Innovation Journal, 17(1), 2-18.

Rogers, E. M. (2003 [1962]). Diffusion of innovations. New York: Free Press.

Røvik, K. A. (2016). Knowledge Transfer as Translation: Review and Elements of an Instrumental Theory. International Journal of Management Reviews, 18(3), 290-310.

Stake, R. E. (1995). The art of case study research. Sage.

Star, S.L. (2010). This Is Not a Boundary Object: Reflections on the Origin of a Concept. Science, Technology 83 Human Values, 35 (5), 601-17. 
Strauss, A.L., \& Corbin, J. (1990) Grounded theory research: Procedures, canons and evaluation criteria. Zeitschrift für Soziologie, 19(6), 418-27.

Sørensen, E., \& Torfing, J. (2011). Enhancing collaborative innovation in the public sector. Administration and Society, 43(8), 42-868.

Torfing, J. (2016) Collaborative innovation in the public sector. Washington, DC: Georgetown University Press.

Torfing, J. (2019) Collaborative innovation in the public sector: the argument, Public Management Review, 21 (1), 1-11.

Torfing, J. \& Triantafillou, P. (2013) What's in a Name? Grasping New Public Governance as a Political-Administrative System. International Review of Public Administration, 18 (2), $9-25$.

Von Hippel, E. (2005) Democratizing Innovation. Cambridge, MA: MIT Press.

Voorberg, W. H., V. J. Bekkers, and L. G. Tummers (2015) "A Systematic Review of Co-Creation and Co-Production: Embarking on the Social Innovation Journey." Public Management Review 17 (9): 1333-1357

Wegrich, K. (2019) The blind spots of collaborative innovation, Public Management Review, 21(1), 12-20.

Weick, K. E. (1995). Sensemaking in organizations. Thousand Oaks, CA: Sage.

World Health Organization. (2017). Global action plan on the public health response to dementia 2017-2025.

Wæraas, A., \& Nielsen, J. A. (2016). Translation Theory 'Translated': Three Perspectives on Translation in Organizational Research. International Journal of Management Reviews, 18(3), 236-270.

Yin, R. K. (2009). Case study research: Design and methods. Los Angeles: Sage. 


\section{Biographies}

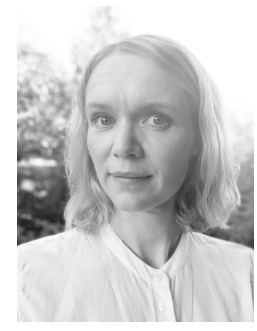

Maria Taivalsaari Røhnebæk. Maria Taivalsaari Røhnebæk is a postdoctoral fellow at Inland Norway University of Applied Sciences. She holds a master's degree in Social Anthropology and a $\mathrm{PhD}$ in Technology, Innovation and Culture from the University of Oslo. Her research focuses on innovation and digitalization in public services, with emphasis on welfare, care and social services. She has conducted extensive fieldwork in India and Norway, and she is presently working on research projects focusing on innovation, service design and co-creation in public services such as dementia care and welfare services.

CRediT Statement: Conceptualization, Methodology, Formal analysis, Investigation, Writing. 